2020-03-23

\title{
Longitudinal Diary Data
}

\author{
Bradwell, Hannah
}

http://hdl.handle.net/10026.1/15893

$10.1145 / 3371382.3378256$

Companion of the 2020 ACM/IEEE International Conference on Human-Robot Interaction ACM

All content in PEARL is protected by copyright law. Author manuscripts are made available in accordance with publisher policies. Please cite only the published version using the details provided on the item record or document. In the absence of an open licence (e.g. Creative Commons), permissions for further reuse of content should be sought from the publisher or author. 


\section{Longitudinal diary data: Six months real-world implementation of affordable companion robots for older people in supported living}

\author{
Hannah L. Bradwell \\ Faculty of Health \\ University of Plymouth \\ hannah.bradwell@plymouth.ac.uk
}

\author{
Serge Thill \\ Donders Centre for Cognition \\ Radbound University \\ s.thill@donders.ru.nl
}

\author{
Ray B. Jones \\ Faculty of Health \\ University of Plymouth \\ ray.jones@plymouth.ac.uk
}

\begin{abstract}
Companion robots have potential for improving wellbeing within aged care, however literature focuses on shorter-term studies often using relatively expensive platforms, raising concerns around novelty effects and economic viability. Here, we report ecologically valid diary data from two supported living facilities for older people with dementia or learning difficulties. Both sites implemented Joy for All robot animals and maintained diaries for six months. Entries were analysed using thematic analysis. We found robot use increased over the six months, changing from short, structured sessions to mainly permanent availability. Thus previously reported concerns on novelty were not warranted. Both sites reported positive outcomes including reminiscence, improved communication and potential wellbeing benefits (reduced agitation/anxiety). Incidences of negative response included devices described as 'creepy.' Devices appeared sufficiently robust for prolonged daily use with multiple users. Overall, we provide insight into real-world implementation of affordable companion robots, and longitudinal development of use.
\end{abstract}

\section{KEYWORDS}

Companion robots, older people, aged care, wellbeing, robopets

\section{ACM Reference format:}

Hannah L. Bradwell, Rhona Winnington, Serge Thill and Ray B. Jones. 2020. Longitudinal diary data: Six months real-world implementation of affordable companion robots for older people in supported living. In ACM/IEEE International Conference on Human-Robot Interaction Companion Proceedings (HRI'20), March 23-26 2020, Cambridge, UK.

ACM, New York, NY, USA, 3 pages.

https://doi.org/10.1145/3371382.3378256

\section{Introduction}

Robots have potential as a technological aid in meeting increasing health and social care demand [1], particularly companion robots $[2,3]$. Paro, the robot seal, is the most well researched example [4]. Studies suggested numerous benefits of interacting with Paro, particularly for older people with dementia $[5,6,7,8,9,10]$. However, there is limited availability of longitudinal 'real-world' companion robot studies that are needed due to potential impact of novelty [11]. Many previous studies with Paro are well controlled trials [4], over shorter time frames [5, 8, 9, 12, 13]. Thus, insufficient attention had been paid to novelty effect [14]. Wada et al. [6] provide an exception (12 months Paro use in older peoples care facility), however researchers controlled the intervention and dose (1 hour on a prepared desk, two days a week), and thus did not

Permission to make digital or hard copies of part or all of this work for personal or classroom use is granted without fee provided that copies are not made or distributed for profit or commercial advantage and that copies bear this notice and the full citation on the first page. Copyrights for third-party components of this work must be honored. For all other uses, contact the Owner/Author.

HRI '20 Companion, March 23-26, 2020, Cambridge, United Kingdom

(C) 2020 Copyright is held by the owner/author(s).

ACM ISBN 978-1-4503-7057-8/20/03. https://doi.org/10.1145/3371382.3378256 observe 'real-world' use. Results suggested Paro was robust and engaging enough for long-term use, but comparable results are lacking for alternative devices. Although Mervin et al. [15] demonstrated Paro was a cost effective agitation intervention for older people (10-week study), real-world stakeholders (care home managers, staff, older people, family members), have reported to us that the price of around $£ 5000$ is prohibitive to purchase. This concurs with concerns noted by Moyle et al. [16], highlighting importance of research with more affordable potential alternatives. Addressing these concerns is our core contribution: we assessed 'real-world' longitudinal use, of high ecological validity, with affordable companion robots, to provide insights on developing relationships, novelty, robustness and longer-term real-world use.

\section{Methods}

\subsection{Design}

Staff in two supported living facilities (sites A, B) that acquired affordable companion robots $(\sim £ 100)$ maintained diary entries over six months. Participants were care staff/site managers, who consented to share data. Staff observations were used as proxy for end-users with reduced written/verbal communication abilities. This is a resource efficient way of collecting observational data for a long-term study. Moyle et al. [17] also reported care staff ability to note effects of robot interaction. Ethical approval was received from the relevant University ethics committee.

\subsection{Materials \\ Robots: (Figure 1).}

Figure 1: Joy for All

(JfA) dog and cat.

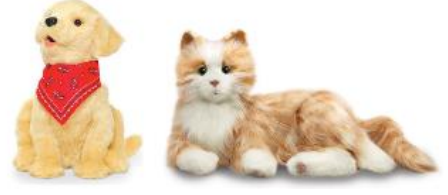

Diaries: Staff recorded observations in physical diaries, a method used previously [18], and valuable for usage scenarios, allowing naturalistic assessment of engagement and experience [19]. We requested staff record date, reason for use, duration and comments.

\subsection{Participants and Settings}

The two sites care for older adults with dementia or learning difficulties in supported living facilities: individual flats with communal area and care staff/management on site. Site A cares for 64 (51 female, 13 male) individuals. Robot interactions were available daily, with group sizes ranging from 14-40. Site A purchased one JfA cat and one dog, and later purchased an additional cat. Site B cares for 30 (18 female, 12 male) individuals with additional day-care customers attending. Site B purchased one JfA cat, group sizes ranged from 11-60 (including day-care customers), with interaction opportunities twice a week.

First accepted 3/1/20 
Table 1: Themes with example evidence. Further evidence at: https://bit.ly/361GMjR

\begin{tabular}{|c|c|c|c|}
\hline Theme & Initial Codes & Interpretation & $*(\mathrm{R})$ indicates resident quote recorded by staff \\
\hline $\begin{array}{l}\text { Positive } \\
\text { Outcomes }\end{array}$ & $\begin{array}{l}\text { Entertainment, pleasure, } \\
\text { reminiscence, } \\
\text { communication, emotions }\end{array}$ & $\begin{array}{l}\text { Reflects positive effects attributed to } \\
\text { interaction. Suggests real-world impact } \\
\text { on emotions and communication }\end{array}$ & $\begin{array}{l}\text { "They make people laugh" "They bring back lovely memories and emotions" "Having the dog } \\
\text { encouraged three people to talk about pets they had previously" "Enjoyed by many" } \\
\text { "She would talk to and stroke [the cat] and become a lot more verbal" }\end{array}$ \\
\hline Acceptability & $\begin{array}{l}\text { Acceptance, requesting } \\
\text { animals, ownership, } \\
\text { facilitator bonding }\end{array}$ & $\begin{array}{l}\text { Devices demonstrated good real-world } \\
\text { acceptability by staff and clients }\end{array}$ & $\begin{array}{l}\text { "[Names] requested the animals, they want to hold them" "Sat for hours petting the cat" } \\
\text { "Insistent she wanted one" "An estimated } 80 \% \text { of clients loved the cat" "Formed a strong bond } \\
\text { and attachment" "I [staff] was surprised how protective I felt towards the cat" }\end{array}$ \\
\hline $\begin{array}{l}\text { Wellbeing } \\
\text { Use }\end{array}$ & $\begin{array}{l}\text { Easing anxiety, } \\
\text { distraction, alleviating } \\
\text { moods }\end{array}$ & $\begin{array}{l}\text { Apparent wellbeing outcomes attributed } \\
\text { to interaction }\end{array}$ & $\begin{array}{l}\text { "A good distraction" "Anxiety eased" "We have used the cats to de-escalate an emotional } \\
\text { situation" "It really seemed to calm her down" "She was crying, shouting, swearing [sic]. } \\
\text { Immediately her body language changed, she was relaxed, smiling, within seconds, she was } \\
\text { laughing" "Deescalated the whole situation and worked really, really well" "Very therapeutic" }\end{array}$ \\
\hline $\begin{array}{l}\text { Change in } \\
\text { Use }\end{array}$ & Change in use & $\begin{array}{l}\text { No novelty effect, early months detail } \\
\text { structured } 1-2 \text { hour sessions, then change } \\
\text { to robots continually present and in-use }\end{array}$ & $\begin{array}{l}\text { "1-2 group session" "2 hours" "Present all day" "Very much part of the service" } \\
\text { "Part of the home" "As normal pets would be" "Have just become part of the norm" } \\
\text { "Sitting on laps as normal pets world" }\end{array}$ \\
\hline $\begin{array}{l}\text { Negative } \\
\text { Responses }\end{array}$ & $\begin{array}{l}\text { Negative response, } \\
\text { unnecessary distraction, } \\
\text { gender difference, } \\
\text { jealousy }\end{array}$ & $\begin{array}{l}\text { Some negative responses, minority of } \\
\text { records, two cases of extreme negative } \\
\text { responses were from males }\end{array}$ & $\begin{array}{l}\text { "Creepy"(R) "He himself [resident] would wring its neck and tear its head off" "That horrible } \\
\text { thing"(R) "Smash it up"(R) "It would just be a time waster"(R) "I would be fussing it all day, } \\
\text { so wouldn't get any housework done"(R) "Very reluctant to allow others to take the cat" } \\
\text { "Everyone wants them at the same time" }\end{array}$ \\
\hline Practicalities & $\begin{array}{l}\text { Cost, robustness, } \\
\text { cleanliness }\end{array}$ & $\begin{array}{l}\text { Price too high for some older people } \\
\text { themselves, devices appeared robust }\end{array}$ & $\begin{array}{l}\text { "Disappointed in the price" "The cats are looking a little bit loved, but the dog is still looking } \\
\text { perky" "They are doing well, but I could imagine they get dirty quite quickly" }\end{array}$ \\
\hline
\end{tabular}

\subsection{Procedure}

Robots were available within communal areas, staff also offered interactions to seated residents. We did not specify an intervention dose, rather, we simply observed how real-world use developed.

\subsection{Data Collection and Analysis}

Observations were conducted daily at Site A and twice weekly at Site B, and reported in diary entries by two members of staff at each site, using event-based sampling [19], where data-collection occurred after observations. Diaries were collected after six months and a short interview conducted with the Site A manager. In total, 35 diary entries were recorded, with additional interview data. Some weeks lacked diary entries, this may reflect annual leave of reporting staff, or methodological limitations. Diary and interview data were collated and analysed using thematic analysis, common threads were identified through familiarisation, code forming and collating into themes, before checking, defining and reporting [20].

\section{Results}

We report identified themes in Table 1. Of note, frequency of positive remarks far outweighed negatives, with 36 counts for the Positive Outcomes theme ("generated a lot of conversation"), 45 for Acceptability and 24 for Wellbeing Use ("anxiety eased"), whilst evidence for Negative Responses totalled 18, six of which were completely negative comments ("creepy" "smash it up"), four related to jealousies, four to robots as time-wasters and the remaining to reluctance or hesitations. With reference to Change in Use, staff entries report structured " 1 -2hour" sessions during the first two/three months, progressing to robots "present all day" by month three, with usage in this manner continuing for study duration. Entries suggested full acceptance of devices as "part of the norm" "as normal pets would be" by months four and five.

\section{Discussion and Conclusion}

This study provided important long-term, real-world data on using affordable companion robots with older people, providing initial insights into robot acceptance over longer time periods. Our study suggested JfA devices saw acceptance and use increasing over six months, with no disuse one would expect if their acceptance was only driven by a novelty effect [21]. Despite this general acceptance, our evidence of negative responses is interesting, and congruent with previous research [17]. This would suggest such devices are not suitable for everyone. Ethical debate on companion robot use raised issues with older people, particularly with dementia [22], perceiving and interacting with robots as live animals. Some authors think this does users a disservice [23], but we have no evidence of this, and staff collaborators (cognitively intact younger adults) also bonded with devices and perceived them as social agents. Thus this effect is not limited to the cognitively impaired, perhaps less an issue of deception, being a natural response to intentionally designed social agents.

We did not measure wellbeing outcomes quantitatively through validated measures, however, as Moyle et al. [17] noted some benefits can be missed by selected psychometrics, recommending staff and family member input. Staff reports in our study support the potential for JfA devices to provide wellbeing benefits in reducing anxiety, agitation, and alleviating moods. These outcomes have been reported previously for Paro [5, 6]. Our study demonstrates the potential for less sophisticated, more affordable devices to provide a possible alternative.

A limitation of our study is use of only two sites, limiting generalizability, however, clients involved were still relevant endusers (older people, primarily with dementia). This study does however demonstrate scope for wider use of such devices (supported living, learning difficulties). This study is also limited by lacking data on which client is being referred to in each entry, making it uncertain if entries refer to the same individual during different episodes or many different people. An implication of this study is potential for more wide-spread adoption of such devices, and support provided for less sophisticated devices to be developed and researched for this purpose, knowing that certain levels of sophistication may be unrequired for acceptability [24] or even potentially, desired wellbeing results.

\section{ACKNOWLEDGMENTS}

We thank our collaborators for maintaining reflections of their observations. This study contributed to the Ehealth Productivity and Innovation in Cornwall and the Isle of Scilly project, part funded by the European Regional Development Fund. 


\section{REFERENCES}

[1] E. Broadbent, R, Stafford and B. MacDonald (2009). Acceptance of Healthcare Robots for the Older Population: Review and Future Directions. International Journal of Social Robotics, 1(4), 319-330.

[2] J. Broekens, M. Heerink and H. Rosendal (2009). Assistive social robots in elderly care: A review. Gerontechnology, 8(2), 94-103.

[3] W. Moyle, M. Cooke, E. Beattie, C. Jones, B. Klein, G. Cook, et al. (2013). Exploring the Effect of Companion Robots on Emotional Expression in Older Adults With Dementia: A Pilot Randomized Controlled Trial. Journal of Gerontological Nursing, 39(5), 46-53.

[4] L. Pu, W. Moyle, C. Jones and M. Todorovic (2018). The Effectiveness of Social Robots for Older Adults: A Systematic Review and MetaAnalysis of Randomized Controlled Studies. The Gerontologist, 59(1), e37-e51.

[5] N. Jøranson, I. Pedersen, A.M. Rokstad and C. Ihlebaek (2015). Effects on Symptoms of Agitation and Depression in Persons With Dementia Participating in Robot-Assisted Activity: A Cluster-Randomized Controlled Trial. J Am Med Dir Assoc, 16(10), 867-73.

[6] K. Wada, T. Shibata, T. Saito, K. Sakamoto and K. Tanie (2005). Psychological and Social Effects of One Year Robot Assisted Activity on Elderly People at a Health Service Facility for the Aged. Proceedings of the 2005 IEEE International Conference on Robotics and Automation; 2005; Barcelona, Spain.

[7] T. Saito, T. Shibata, K. Wada and K. Tanie (2003). Relationship between interaction with the mental commit robot and change of stress reaction of the elderly. Proceedings of IEEE International Symposium on Computational Intelligence in Robotics and Automation, CIRA; 2003 Kobe, Japan, 119-24.

[8] A. Liang, I. Piroth, H. Robinson, B. MacDonald, M. Fisher, U.M. Nater, et al. (2017). A Pilot Randomized Trial of a Companion Robot for People With Dementia Living in the Community. Journal of the American Medical Directors Association, 18(10), 871-8.

[9] S. Petersen, S. Houston, H. Qin, C. Tague and J. Studley (2017). The Utilization of Robotic Pets in Dementia Care. Journal of Alzheimer's Disease, 55(2), 569-74

[10] H. Robinson, B. MacDonald and E. Broadbent (2015). Physiological effects of a companion robot on blood pressure of older people in residential care facility: a pilot study. Australasian Journal On Ageing, 34(1), 27-32.

[11] P. Baxter, J. Kennedy, E. Senft, S. Lemaignan and T. Belpaeme (2016) From characterising three years of HRI to methodology and reporting recommendations. $201611^{\text {th }}$ ACM.IEEE Internation Conference of Human-Robot Interaction (HRI); Christchurch, New Zealand, 391-398.
[12] K. Thodberg, L.U. Sorensen, J.W. Christensen, P.H. Poulsen, B. Houbak, V. Damgaard, et al. (2016). Therapeutic effects of dog visits in nursing homes for the elderly. Psychogeriatrics, 16(5), 289-97.

[13] W. Moyle, C.J. Jones, J.E. Murfield, L. Thalib, E.R.A. Beattie, D.K.H. Shum, et al. (2017). Use of a Robotic Seal as a Therapeutic Tool to Improve Dementia Symptoms: A Cluster-Randomized Controlled Trial J Am Med Dir Assoc, 18(9), 766-73.

[14] R. Kachouie, S. Sedighadeli, R. Khosla and M-T. Chu (2014). Socially Assistive Robots in Elderly Care: A Mixed-Method Systematic Literature Review. International Journal of Human-Computer Interaction, 30(5), 369-93.

[15] M.C. Mervin, W. Moyle, C. Jones, J. Murfield, B. Draper, E. Beattie, et al. (2018). The Cost-Effectiveness of Using PARO, a Therapeutic Robotic Seal, to Reduce Agitation and Medication Use in Dementia: Findings from a Cluster-Randomized Controlled Trial. Journal of the American Medical Directors Association, 19(7), 619-22.

[16] W. Moyle, M. Bramble, C. Jones and J. Murfield (2016). Care staff perceptions of a social robot called Paro and a look-alike Plush Toy: a descriptive qualitative approach. Aging \& Mental Health, 22(3), 330-335.

[17] W. Moyle, C. Jones, J. Murfield, L. Thalib, E. Beattie, D. Shum and B Draper (2017). Using a therapeutic companion robot for dementia symptoms in long-term care: reflections from a cluster-RCT. Aging \& mental health, 23(3), 329-336.

[18] M. Birks, M. Bodak, J. Barlas, J. Harwood and M. Pether (2016). Robotic Seals ad Therapeutic Tools in an Aged Care Facility: A Qualitative Study. Journal of Aging Research, 2016, doi.org/10.1155/2016/8569602.

[19] T. Lischetke (2014). Daily Diary Methodology. In, A. C. Michalos (Ed.) Encyclopedia of Quality of Life and Well-being Research, Dordrecht, Netherlands, 1413-1419.

[20] V. Braun and V. Clark (2006). Using thematic analyss in psychology Qualitaive Research in Psychology, 3(2), 77-101.

[21] R. Sparrow and L. Sparrow (2006). In the hands of machines? The future of aged care. Minds and Machines, 16(2), 141-61.

[22] N. Sharkey and A. Sharkey (2012). The eldercare factory. Gerontology, 58(3), 282-8.

[23] R. Sparrow (2002). The March of the Robot Dogs. Ethics and Information Technology, 4(4), 305-18.

[24] H.L. Bradwell, K.J. Edwards, R. Winnington, S. Thill and R.B. Jones (2019). Companion robots for older people: the importance of usercentred design demonstrated through observations and focus groups comparing preferences of older people and roboticists in South West England. BMJ Open, 9(9), e032468. 